\title{
Review of the Influence of Large-scale Grid-connected Photovoltaic Power Plants on Power Grid
}

\author{
Xingyu Liu ${ }^{1}$, Tieyan Zhang ${ }^{2}$, Baiyu Gao ${ }^{1}$ and Yue $\operatorname{Han}^{3}$ \\ ${ }^{1}$ Department of Marketing, State Grid Liaoning Electric Power Supply Co. Ltd., \\ Shenyang China \\ ${ }^{2}$ Shenyang Institute of Engineering, Shenyang, China \\ ${ }^{3}$ Electric Power Research Institute, State Grid Liaoning Electric Power Supply Co. \\ Ltd., Shenyang, China \\ zty@sie.edu.cn
}

\begin{abstract}
With the increase of photovoltaic grid-connected capacity, photovoltaic generation will bring many impacts on distribution network. In this paper, the influence of large-scale grid-connected photovoltaic power plants on power grid is reviewed. First, through researching the basic structure and operating characteristic, the paper introduces the operation mechanism of large-scale grid-connected photovoltaic power plants. Then the paper analyzes the influence of large-scale grid-connected photovoltaic power plants on the grid from the distribution grid planning and scheduling, power quality and power system protection. In the end, the paper summarizes some new problems and discusses and prospects the development trends on the large-scale grid-connected photovoltaic power plants.
\end{abstract}

Keywords: photovoltaic power plant, distribution grid planning and scheduling, power quality, power system protection

\section{Introduction}

In recent years, with the depletion of fossil fuels and the deterioration of environmental issues, the demand for renewable energy is increasing largely. While many countries have made decision that human large-scale develop and utilize the renewable energy of represented by the wind and solar, a new power system era of regarding the new energy generation as a symbol is coming.

According to the latest statistics, in 2015 the global cumulative PV installed capacity of up to $200 \mathrm{GW}$ is about two times than that of in 2012. Although the PV industry has been ups and downs in 2010, in the long term, PV industry remains strong growth momentum and is expected that cumulative PV installed capacity will be more than $450 \mathrm{GW}$ in 2017. In our country, the government fiscal subsidies and the priority grid policy make a powerful incentive for PV industry so that PV installed capacity is on the rise [1], and by the end of 2007, China's total installed capacity of PV systems reach 10 million kilowatts. In 2012, China has become the one of the second largest PV application market in the world. On July 15st 2013, China promulgated "State Council on promoting the healthy development of a number of opinions photovoltaic industry," which proposed that PV installed capacity would add about $10 \mathrm{GW}$ a year from 2013 to 2015, and it will be more than $35 \mathrm{GW}$ by 2015 [2-5]. And several years ago, "national energy development plan" stipulated: large-scale solar photovoltaic power plant is one of the key development areas from 2010 to 2020. These show that photovoltaic power plants have been large-scale. Several megawatt grid-connected photovoltaic power plants have been started or run in Qinghai, Gansu, Ningxia and other places, and China has also developed some 
corresponding grid technology requirements [6]

Photovoltaic grid-connected technology has become the main form of the PV application. However, with the influence of the time and the climate change, photovoltaic power has the output characteristic of randomness, volatility and intermittent, so it makes more difficult to control and belongs to the uncontrollable generators. With the rapid increase of distributed photovoltaic grid-connected capacity, photovoltaic power generation will bring a great impact on distribution networks. In addition, because of the different operation mechanism between photovoltaic power plants and conventional power plants, the large-scale grid-connected photovoltaic power plants will bring great challenges for distribution networks' security and stability operation [7-14].

This paper combined with current research on large-scale grid-connected photovoltaic power plants. Through researching and analysis the basic structure and operating characteristics, the paper mainly reviews the impact of large-scale grid-connected photovoltaic power plants on the grid. It will provide many references for carrying out further depth study in the future.

\section{Photovoltaic Array Model}

Photovoltaic cells are the smallest components of photovoltaic array, which are assembled into photovoltaic modules. Then, in the form of series-parallel connection, photovoltaic modules will constitute a photovoltaic array, followed by the formation of photovoltaic power plants [3]. The equivalent circuit of the photovoltaic cell is shown in Figure 2. In the figure: is photocurrent; is diode reverse saturation current; is equivalent series resistance of the photovoltaic array; is equivalent parallel resistance for the photovoltaic array; is the output current of the PV array; is output voltage of the PV array.

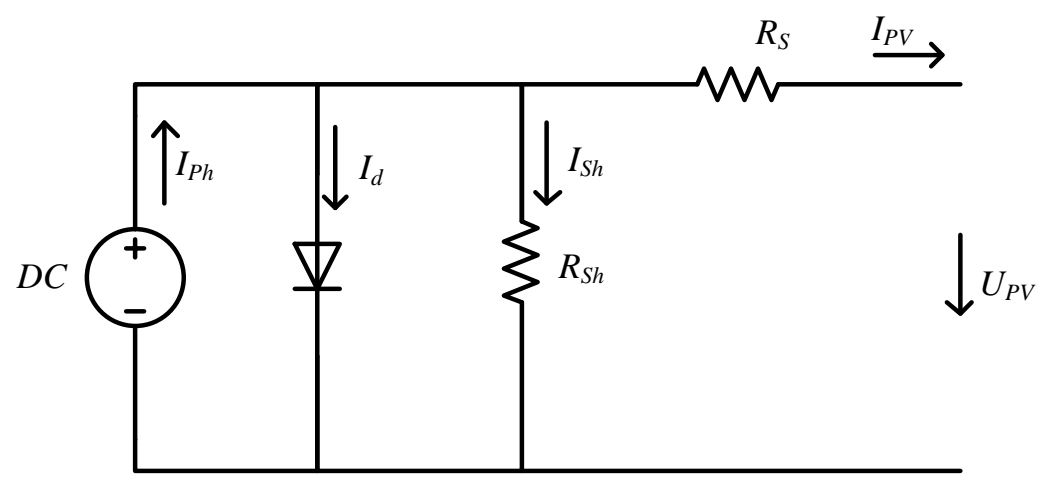

Figure 2. The Equivalent Circuit of the Photovoltaic Cell

The volt ampere characteristics of photovoltaic cells can be obtained from the circuit diagram:

Let us suppose that the $\mathrm{n}$ photovoltaic cells series into one group, and the $\mathrm{m}$ groups parallel into a photovoltaic array. So we will obtain the mathematical model of the photovoltaic array [15] [16]

In the formula (2), (3): $\mathrm{n}$ is the number of tandem photovoltaic module; $\mathrm{m}$ is the number of components in parallel PV; $\mathrm{A}$ is the PN junction diode ideality factor and is a dimensionless constant; $\mathrm{K}$ is the Boltzmann's constant; $\mathrm{T}$ is the temperature of array 
working environment; $\mathrm{q}$ is the electron charge quantity.

Photocurrent related to many factors, among that the two most important factors are solar irradiance and ambient temperature. The formula as follows [17]:

In the formula (4): $S$ is an array of solar irradiance at work; is the reference values for solar irradiance; is the resistant optical current reference value; is the temperature coefficient of the short-circuit current and is related to the battery materials; is the ambient temperature reference value which is $25^{\circ} \mathrm{C}$ or $273 \mathrm{~K}$ usually.

Through the photovoltaic array mathematical model, we can know that the effect of environmental conditions on photovoltaic power plants' output is obvious. As shown in Figure 3. In the (a), invariant is light intensity and in the (b), invariant is temperature. When the solar irradiance and ambient temperature have changed, the output voltage of the photovoltaic array has a change, and the output power also varies. Therefore, in order to improve the efficiency of photovoltaic power generation, it is significant that we analysis the basic structure and output characteristic of large-scale grid-connected photovoltaic.

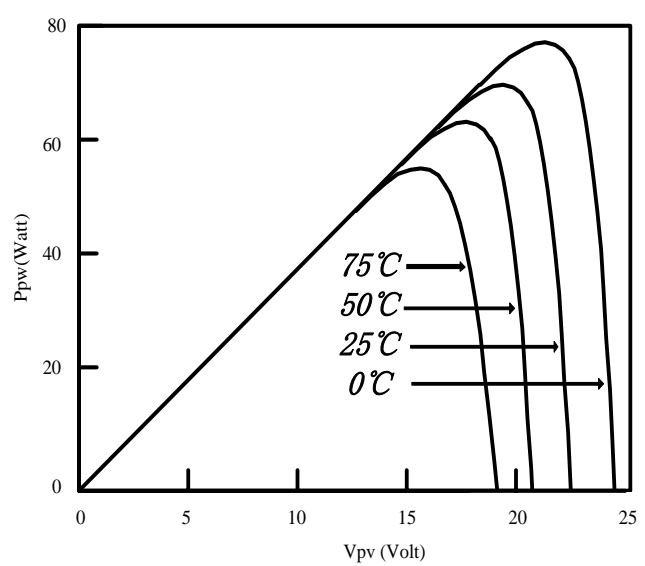

(a)

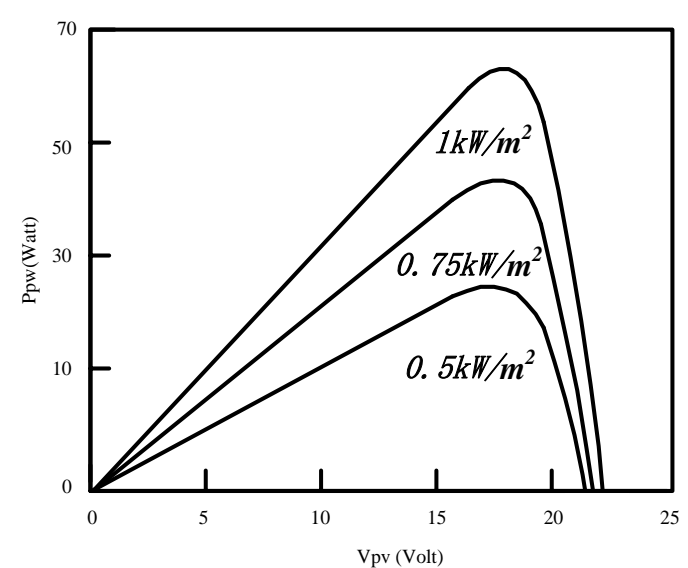

(b)

Figure 3. Photovoltaic Output with the Change of Temperature and Light Intensity

\section{The Grid-Connected Basic Structure and Operating Characteristics of Large-Scale Photovoltaic Plants}

\subsection{The Grid-Connected Basic Structure}

Photovoltaic is a kind of photovoltaic effect which is based on semiconductor converting solar radiation into electricity directly. In order to meet the power requirements, the direct current of photovoltaic array is converted into alternating current and alternating current is switched on the grid directly through a transform. Photovoltaic systems composed of the photovoltaic array, direct current combiner boxes, inverters, transformers load and transmission lines. Figure 1 is the basic structure of large-scale grid-connected photovoltaic power plant. 


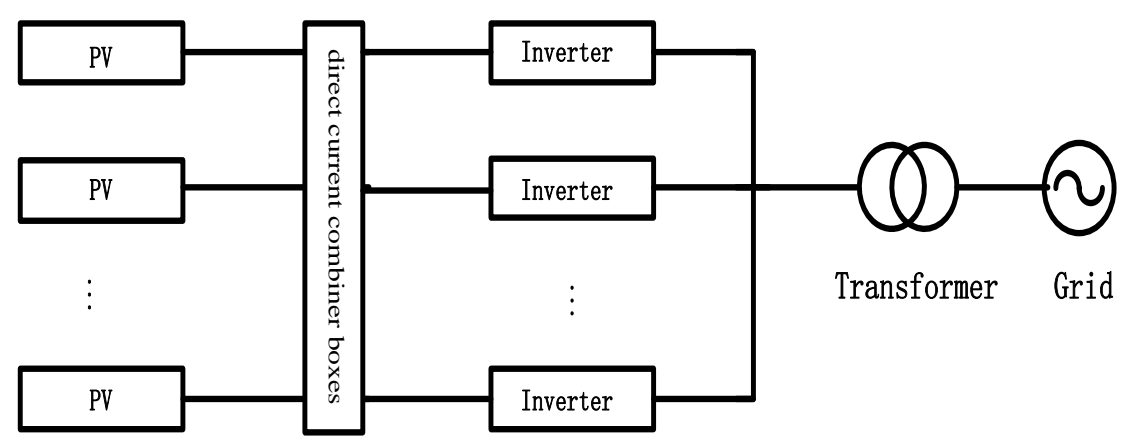

Figure 1. Basic Structure of Large-Scale Grid-Connected Photovoltaic Power Plant

\subsection{The Operating Characteristics}

Comparing with the small-scale grid-connected photovoltaic power generation systems, large-scale grid-connected photovoltaic power plant can make full use of solar energy, and using Maximum Power Point Tracking (MPPT) technology improves the efficiency of the system. We can not only use the technology of inverters in parallel, centralized management and control but also make full use of temporal distribution characteristics of solar at the appropriate conditions and use the energy storage technology to make photovoltaic power plant play a role that it can provide power generation in the peak period of electricity consumption and compensate reactive power to meet the needs of grid-friendly role. Specifically, large-scale grid-connected photovoltaic power plant has the following operational characteristics:

(1) Large area photovoltaic array lead performance to vary [18]. On the one hand, the difference of the actual working environment of small sectional array leads the difference of photovoltaic cell operating temperature, duration of sunshine and sunlight intensity, eventually, it makes the integral characteristics vary. On the other hand, the difference of manufacturers lead to produce different types of photovoltaic cells so that it brings the effect on inherent characteristics of the photovoltaic array, which is not satisfied with ideal requirements of combination performance photovoltaic array [19].

(2) The grid-connected inverter has large capacity and multi-type. Large-scale grid-connected photovoltaic power plant usually use the methods that grid-connected inverter combine with many low-voltage inverters to boost to the high pressure (10 $\mathrm{kV} / 35 \mathrm{kV}$ ) through the transformer [20]. Combination of multiple inverters is aimed at increasing system redundancy, and by the partial shutdown of the inverter, it can achieve conversion of high efficiency at the low light. But multiple inverters in parallel operation will produce circulation, and a lot of harmonics.

(3) The local power grid will be brought some negative effects, such as power quality problems [21], the voltage fluctuations caused by the instability of power output [22], an island [23] and so on. Photovoltaic power generation as a small time scale, non-rotating inertia power mode, when the grid scale comes to a certain extent, for the safe operation of the power grid will be a challenge [24].

\section{The Influence of Large-Scale Grid-Connected Photovoltaic Power Plants on Power Grid}

With the access of large-scale grid-connected photovoltaic power generation system, traditional grid will be brought some influences inevitably, such as planning and design, power quality, power system protection, scheduling operation and so on. It is a significant work that studying and mastering these effects lay the foundation for the further development of the grid, and according to their own needs of security and stability, 
propose and develop relevant technical requirements for grid-connected of photovoltaic power plants

\subsection{The Impact on Planning and Scheduling Preparation}

That large-scale grid-connected photovoltaic power plants connect to the grid will change the trend of distribution grid and load characteristics and lead photovoltaic to reverse power. These will impact on planning and scheduling operation of distribution grid [25].

\section{(1) The impact on planning}

On the one hand, the randomness of photovoltaic output changes the way of power grid planning [26]. Power grid planning must meet the requirements of the reliability of power supply that loss of load probability should be kept in a relatively small range. However, as a kind of the electrical source, grid-connected photovoltaic power plants are affected by the weather, terrain, location and other factors greatly. And, with the increasing of capacity, the number of PV arrays in parallel is also increasing. So the area of photovoltaic array is also increasing so that the output of a certain area of the array within the same day time at the different points of time will differ, and therefore a large area of the photovoltaic array will exhibit the different output characteristics with single photovoltaic cell or a small area of the PV array. In addition due to the difference of photovoltaic modules will make this feature more obvious [27]. The feature makes the conventional MPPT technology can not normally get the maximum power point of a large-scale photovoltaic power generation. Therefore, the output power of the photovoltaic plant has the great uncertainty and volatility so that can't guarantee the reliability of supply.

On the other hand, the traditional generation scheduling depends on the accurate prediction of the load. Load forecasting as a basis for planning and design of the power grid, whether or not we can predict the load accurately is a prerequisite for network planning. Due to the electricity from the grid-connected photovoltaic systems can often balance out some of the local load on the spot [28], and grid-connected photovoltaic power generation affected by climate change significantly. So the total load of the entire grid has more variability and randomness, making it more difficult to forecast short-term load. Eventually, rational development of power generation plan will be brought greater difficulty.

\section{(2) The impact on scheduling operation}

Due to the existing photovoltaic unit without the function of scheduling automation, and with the increasing of photovoltaic power plants' capacity, the grid frequency and voltage stability will be brought greater influence. However, because of the limit of technical level, the current large-scale photovoltaic systems don't have the ability of adjusting frequency and voltage. There is no doubt that schedulable generation capacity will be reduced thereby increasing the difficulty of the distribution grid control and scheduling operations [29].

\subsection{The Impact on Power Quality}

(1) The impact on voltage

Starting large-scale photovoltaic power plants or changing the output of photovoltaic power plants can cause voltage variations. On the one hand, the output power of large-scale photovoltaic arrays is greatly affected by the solar radiation at day and night, and continuing to occur with the solar irradiance changing. If the sunshine mutation cause suddenly power decrease or loss, in general, this part of the power shall be provided by local distribution transformers. Thus installation at the bus or even the entire distribution grid voltage may be destroyed. On the other hand, in the state of steady operation, the 
traditional distribution grid voltage of each load point is reduced gradually along the direction of the flow path. Because of the access of large-scale photovoltaic make the transmission power on the feeder decrease and lead the voltage of each load point to rise, which will affect the voltage of each load point, thereby causing voltage fluctuations in the distribution grid. If the proportion of photovoltaic output is larger, its output instability will cause load current on the distribution lines to be vulnerable to fluctuations, thereby increasing the difficulty of the grid voltage adjustment during normal operation. If the voltage adjustment is not smoothly, voltage of distribution grid will be excessive [30].

At the same time due to excepting the voltage adjustment by switching capacitive reactance in the distribution grid, power grid has few other dynamic reactive power conditioning equipment, but the supporting capacity of reactive voltage of photovoltaic power is weak during the actual operation of photovoltaic power, which the risk of voltage quality beyond the limit and voltage instability is larger [31-32]. For the large-scale photovoltaic dispersive merging into distribution grid, the radial grid structure of distribution grid will be changed, which single supply structure will become into a dual power supply or multiple power supply. The distribution magnitude and direction of power current are complex and volatile, so power current has become more difficult to control, thereby affecting the distribution grid voltage quality. There is significant correlation between the degree of influence and location, scale output of photovoltaic access [33-35].

\section{(2) Harmonic pollution}

For photovoltaic grid-connected need to introduce inverter which contains a lot of power electronic components. When direct current transform into alternating current, inverter produce harmonics inevitably to pollute the power grid [36].However, with the increasing of photovoltaic capacity, a large number of power electronic devices widely used will generate a large number of harmonics, and harmonics will add an additional loss of power equipment, thereby great affecting the quality of power. The operating experience of several large-scale photovoltaic power plants from home and abroad shows that though the output current harmonics produced by a single grid-connected inverter is fewer, that by many grid-connected inverters paralleling may also be exceeded [37-38]. Because of the speed of inverter switching slow will cause the output distortion and harmonic generation. In a word, that a large number of inverters paralleling will bring some problems of current harmonics superposition during the large-scale photovoltaic grid-connected [39]. The literature [40] solves the problem mainly through the following two aspects. First, through the use of harmonic suppression circuit and active power factor correction circuit in the inverter eliminate the higher harmonics. Second the higher harmonics and distortion current from the power supply equipment will be eliminated.

\subsection{The Impact on the Power System Protection}

Photovoltaic power generation has become the main form of using solar energy. With the large-scale operation of photovoltaic system, when photovoltaic power capacity is large enough comparing with the distribution grid system capacity, the structure of distribution grid and short-circuit current distribution will be bring a profound impact, thereby affecting the normal operation of the grid of the original protection device.

At present, China's low-voltage distribution grid is largely ungrounded (or arc suppression coil grounding) unilateral power and radiation type power supply network. Substation protection is based on the steamer route three-current protection, which the main feeder is installed on automatic reclosing devices and branch circuit is installed on fuses. Because photovoltaic power play a role on increasing or diversion the fault current, the size, duration and direction of the fault current will be changed, which flowing through the fault current protection device may increase or may decrease and the scope of protection and sensitivity will be also change, thereby bringing issue of the cooperate with 
each other of individual protection devices [41]. Embodying in the following aspects:

(1) The introduction of a large-scale photovoltaic power plant makes distribution grid from the traditional single-supply radiating grid to a two-end or multiport grid, thereby the size, duration and direction of the fault current will change, so that the original feeder protection will be affected, which may lead breaker malfunction, refused to move and lose selectivity [42-47].

(2) Depending on the connection of the transformer, the inverter of connecting with the transformer can form additional ground loops, which affect the zero sequence current or increase the voltage of normal phase to ground during the single phase to ground short circuit fault and will also change the operating characteristics of relay protection [41].

(3) Failure of photovoltaic power plant itself will have an impact on the operation and protection system, thereby increasing the necessary content about protecting power system for the photovoltaic grid-connected inverter of sensitive to disturbance in practical grid-connected photovoltaic systems, including low voltage ride through, excessive harmonic output, excessive direct-current component and phase imbalance protection [41].

(4) When anti-islanding protection time of photovoltaic systems is not coordinated with the device of automatic reclosing, it will cause the asynchronous closing and form a great impact current or voltage between the photovoltaic systems and system power. Under the impact of the current, protective equipment is likely to malfunction to make the automatic reclosing lose the ability to quickly restore transient faults. Meanwhile, the impact of the current is also likely to have fatal impact on the main grid and the inverter or other equipment of photovoltaic grid-connected system [42]. In order to prevent asynchronous closing, for the lines of connecting with the inverters, three-phase reclosing start time or standby power source breaker operating time are more than the inverter anti- islanding protection maximum operating time.

(5) Distributed and high-density photovoltaic systems, often through multiple or a low-voltage distribution line access to the same bus to connect the grid to generate [43]. Due to the photovoltaic generation power affected by the illumination changes is correlation in the same area. High-density photovoltaic systems grid-connected will exacerbate the range ability of local distribution grid current and the range of the voltage fluctuation [45-48]. In addition, if some feeder line of the smaller power load of connecting to the high-density photovoltaic system on the same bus suffer from the short-circuit fault, the upper and lower fuse of connecting to the feeder line can't coordinate, that fuse lose selectivity and short-circuit power of flowing through some the load branch circuit exceed the breaking capacity of the breaker [49].

\section{Conclusion}

Photovoltaic power generation as an important form of the new energy has a good development foreground. However, a large number of photovoltaic grid-connected will bring the impact on safe and reliable operation of the traditional distribution grid. Under the premise in power quality, reliability and safety of the photovoltaic power generation system, the best use of solar resources to generate has a significant. Therefore, this paper aims at the distributed photovoltaic power generation system. Through researching and analysis the basic structure and operating characteristics, the paper mainly reviews the impact of large-scale grid-connected photovoltaic power plants on the grid. In the future, it is necessary to further study the impact, thereby proposing the most effective solutions and making the photovoltaic power generation more secure, stable, high efficiency. On the one hand we should develop a reasonable control strategy which is integrity [50], such as achieving the complementation between wind and solar, making other power the coordination and the balance, etc. On the other hand, we should be devoted to improve 
solar power generation technology, such as energy storage technologies, harmonic suppression, the new grid-connected inverters, etc.

\section{References}

[1] B. Kroposki, A. Vaughn. DG Power Quality, Protection, and Reliability Case Studies Report [R]. National Renewable Energy Laboratory, (2003).

[2] Y. W. Zhao, D. C. Wu, S. C. Wang. Report on China PV Industry Development [J]. Solar Energy, vol. 6, no. 13 (2008).

[3] Z. M. Zhao, J. Z. Liu, X. Y. Sun. Solar Photovoltaic and Its Application [M]. Science Press, (2006).

[4] Z. M. Zhao, Y. L, F. B. He. Overview of Large-scale Grid-connected Photovoltaic Power Plants [J]. Automation of Electric Power Systems, vol. 35, no. 12 (2011).

[5] N. Xie, A. Luo, F. J. Ma. Harmonic Interaction between Large-scale Photovoltaic Power Stations and Grids [J]. Proceedings of the CSEE, vol. 33, no. 34 (2013).

[6] State Grid. Q/GDW 617-2011 Technical rule for photovoltaic power station connected to power grid[S]. China Electric Power Press, (2011).

[7] M. Liserre, R. Teodorescu, F. Blaabjerg. Stability of Photovoltaic and Wind Turbine Grid-connected Inverters for a Large Set of Grid Impedance Values [J]. IEEE Transactions on Power Electronics, vol. 21, no. 1, (2006).

[8] C. S. Wang, P. Li. Development and Challenges of Distributed Generation, the Micro-grid and Smart Distribution System [J]. Automation of Electric Power Systems, vol. 34, no. 2, (2010).

[9] K. Yoshida, K. Kouchi, Y. Nakanishi. Centralized Control of Clustered PV Generations for Loss Minimization and Power Quality [C]. Proceedings of IEEE Power and Energy Society General Meeting. Pittsburgh, USA: IEEE, (2008).

[10] M. Hojo, H. Hatano, Y. Fuma. Voltage Rise Suppression by Reactive Power Control with Cooperating Photovoltaic Generation Systems [C]. Proceedings of the 20th International Conference and Exhibition of Electricity Distribution. Prague, Czech Republic: IEEE, (2009).

[11] W. Zhao. Research on Grid-connected Photovoltaic System [D]. Hefei University of Technology, (2003)

[12] J. M. Carrasco, L. G. Franquelo, J. T. Bialasiewicz. Power Electronics Systems for the Grid Integration of Renewable Energy Sources: a survey [J]. IEEE Transactions on Industrial Electronics, vol. 53, no. 4 (2006).

[13] P. P. Barker, J. M. Bing. Advances in Solar Photovoltaic Technology: an Applications Perspective [C]. IEEE Power Engineering Society General Meeting. San Francisco, USA: IEEE, (2005).

[14] A. Woyte, V. V. Thong, R. Belmans. Voltage Fluctuations on Distribution Level Introduced by Photovoltaic Systems [J]. IEEE Transactions on Energy Conversion, vol. 21, no. 1, (2006).

[15] Y. Zhang, G. Q. Lu, Y. zhang. Influence of Grid Connection of Photovoltaic Power Station on Power Grid Reliability [J]. East China Electric Power, vol. 38, no. 5, (2011).

[16] J. Li, W. Dou, Z. G. Xu. Research On MPPT Methods of Photovoltaic Power Generation System[J]. Acla Energiae Solaris Sinicat, vol. 28, no. 3, (2007).

[17] X. Ai, X. N Han, Y.Y. SUN. Grid Connection Characteristics of Large-Scale Photovoltaic Power Station and Its Low-Carbon Operation and Control Technology [J]. Power System Technology, vol. 37, no. 1 (2013).

[18] Y. Deng, Z. M Zhao, Li. Q Yuan, S. D Hu, X. S. Wang. IGBT Model for Analysis of Complicated Circuits [J]. Proceedings of the CSEE, vol. 30, no. 9 (2010).

[19] M. C. Alonso, J. M. Ruiz, F. Chenlo. Experimental Study of Mismatch and Shading Effects in the I-V Characteristic of a Photovohaic Module [J]. Solar Energy Materials\&Solar Ceils, vol. 90, no. 3 (2006).

[20] M. Y. The Key Technology Research of Photovoltaic Power Generation Grid-network and Parallel [D]. Huazhong University of Science and Technology, (2009).

[21] R. K. Varma, M. Salama, R. Seethapathy. Large-scale Photovoltaic Solar Power Integration in Transmission and Distribution Networks [C]. Proceedings of IEEE Power\&Energy Society General Meeting, July 26-30, Calgary, AB, Canada, (2009).

[22] W. Li, Y. H. Lin. Random Fluctuations on Dynamic Stability of a Grid-connected Photovoltaic Array [C] Proceedings of IEEE Power Engineering Society Winter Meeting, Vol 3January 28 - February 1, Columbus, OH, USA (2001).

[23] W. D. Yang, F. Xue, T. S. Xu. Grid-connected Photovohaie's Influence on Power Systems and Some Related issues [J]. Hydropower Automation and Dam Monitoring, , vol. 33, no. 4, (2009).

[24] S. Achilles, S. Schramm, J. Bebic. Transmission System Performance Analysis for High-penetration Photovohaics [R]. Golden, CO, USA: National Renewable Energy Laboratory, (2008).

[25] W. Chen, X. Ai, T. Wu, H. Liu. Review of Research on Influence of Photovoltaic Grid-connected Power system on Power Grid [J]. Electric Power Automation Equipment, vol. 33, no. 2, (2013).

[26] M. Mcgranachan, T. Ortmeyer, D. Crudle. Renewable Systems InterconnectionStudy [R]. Livermore, USA: Sandia National Laboratories, (2008).

[27] Y. Deng. Research on IGBT Model for Complicated Circuits and a Large Area of the Photovoltaic Array Model [D]. Tsinghua University, (2010). 
[28] W. Huang, Y. L. Sun. Grid Connected Photovoltaic Generation and the Impact on Power System [J] (2012).

[29] P. Zhao, Y. T. Yan. Research on the Influence of Grid-connected Photovoltaic Power System on Power Grid [J] Electrical Engineering, 3, (2009).

[30] X. H. Hu. Distributed Generation Technology and Its Grid-connected Question [J]. Electric Engineering, $10(\mathbf{2 0 0 4})$

[31] Y. T. Tan, Kirschen D S. Impact on the Power System of a Large Penetration of Photovoltaic Generation [C]. IEEE Power Engineering Society General Meeting, Tampa, (2007).

[32] T. Alquthami, H. Ravindra, M. O. Faruque. Study of Photovoltaic Integration Impact on System Stability Using Custom Model of PV Arrays Integrated with PSS/E [C] North American Power Symposium (NAPS), Arlington, (2010).

[33] J. V. Paatero, P. D. Lund. Effects of Large-scale Photovoltaic Power Integration on Electricity Distribution Networks [J]. Renewable Energy, 32 (2007).

[34] J. Widen, E. Wackelgard, J. Paatero. Impacts of Distributed Photovoltaics on Network Voltages: Stochastic Simulations of Three Swedish Low-voltage Distribution Grids [J]. Electric Power Systems Research, vol. 80, no. 12, (2010).

[35] K. Takahashi, R. Nakanishi, K. Okada. Load Flow Method for Distribution System and Its Application for High Penetration of PV Generation [C] Proceeding of the International Conference on Electrical Engineering, HongKong, (2009).

[36] T. Ishikawa. Grid-connected Photovohaic Power Systems: Survey of Inverter and Related Protection Equipments [R]. Tokyo, Japan: Report IEA-PVPs Task (2002).

[37] W. J. Dong, X. M. Bai, N. H. Zhu. Discussion on the Power Quality Under Grid-connection of Intermittent Power Sources [J]. Power System Technology, vol. 37, no. 5 (2013).

[38] R. Varma, M. Salama. Large-scale Photovoltaic Solar Power Integration in Transmission and Distribution Networks [C] Proceedings of IEEE Power and Energy Society General Meeting, Detroit, (2011).

[39] M. Ding, W. S. Wang, X. L. Wang, Y. T. Song, D. Z. Chen, M. Sun. A Review on the Effect of Large-scale PV Generation on Power Systems [J] Proceedings of the CSEE, vol. 34, no. 1, (2014).

[40] J. Liu. Analysis of the Main Factor of Influence Grid-connected PV System Harmonic Level [J]. Electric Engineering, 12 (2009)

[41] Z. Y. Zang, J. D. Huang, X. B. Duan. Influence of Photovoltaie Power Generation System on Relay Protection of Distribution Network During Grid-connecting [J]. Hebei Electric Power, vol. 29, no. 3, ,(2010)

[42] Lei Yi, Zhao Zhengming. Overview of Large-scale PV Integration Key Technologies and Its Impact [J]. Power Electronics, 3 (2010).

[43] Z. G. Shi, X. W. Wang, S. Q. Qiang. Influence of Grid Connected Photovoltaic Power System on Line Protection of Distribution Network [J]. East China Electric Power, vol. 01, no. 38, (2010).

[44] M. Ding, S. Liu. Calculation of Maximum Penetration Level of Multi PV Generation Systems [J]. Power System Technology, vol. 37, no. 4, (2013).

[45] J. A. Peas Lopes, C. L. Moreira, A. G. Madureira. Defining control strategies for microgrids island operation [J]. IEEE Trans on Power Systems, vol.21,no. 2, (2006).

[46] A. D. Hawkes, M. A. Leach. Modelling High Level System Design and Unit Commitment for a Microgrid [J]. Applied Energy, vol. 86, no. 17, (2009).

[47] Q. Chen, L. D. Li, Q. J. Wang. Simulation Model of Photovoltaic Generation Grid-connected System and Its Impacts on Voltage Stability in Distribution Grid [J]. Transaction of China Electrotechnical Society, vol. 28 , no. $3,(\mathbf{2 0 1 3})$.

[48] X. Y. Xu, Y. H. Huang, C. Liu. Influence of Distributed Photovoltaic Generation on Voltage in Distribution Network and Solution of Voltage Beyond Limits [J]. Power System Technology, vol. 34, no. 10, (2010).

[49] S. A. A. Shahriari, M. Abapour, A. Yazdian. Minimizing the Impact of Distributed Generation on Distribution Protection System by Solid State Fault Current Limiter [C] Transmission and Distribution Conference and Exposition, New Orleans, (2010).

[50] Z. Q. Yao, Q. Zhang, X. M. Liu, Research on Simulation of a Three-phase Grid-connected Photovoltaic Generation System Based on PSCAD/EMTDC [J]. Power System Protection and Control, 38, 17 (2010).

\section{Authors}

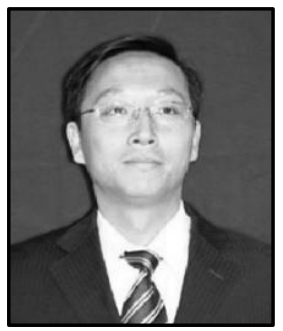

Xingyu Liu was born in 1969. He received bachelor degree of the electric power system and its automation from Xi'an Jiaotong University and master degree of business administration from Liaoning University. Now he is a senior engineer and the director of sales department's marketing department at state grid Liaoning power company, Shenyang, China. His research interests include scheduling of electrical power, smart power grid. 


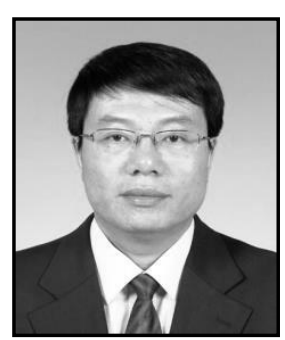

Tieyan Zhang was born in 1962 . He received the $\mathrm{Ph}$. D. degree in control theory and control engineering from Northeastern University, Shenyang, China, in 2007. He is currently a professor of Shenyang University of Technology, Shenyang. His current research interests include fuzzy controls, fault diagnosis on electric power systems, and stability analysis on smart grids.

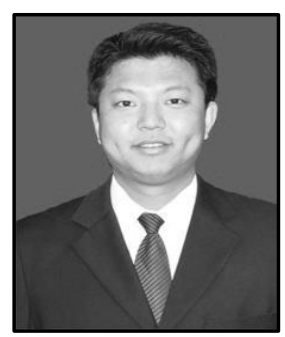

Baiyu Gao was born in July 1978. Now he works in marketing department at state grid Liaoning power company, Shenyang, China. $\mathrm{He}$ received bachelor degree of economics at International Economics and Trade in Liaoning University and in the period he minored in law and got a bachelor's degree of law. During the work, he got professional master degree of engineering Shenyang Agriculture University.

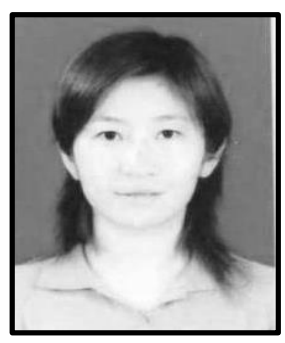

Yue Han received the Master degree in Automation of Electrical Power System from North China Electric Power University, Beijing, China, in 2003. She is currently a senior engineer, working in Liaoning Electric Power Research Institute, Shenyang, China. Her current research interests include On-line Monitoring Technology and artificial intelligence. 